\title{
Pembuatan produk biodiesel dari Minyak Goreng Bekas dengan Cara Esterifikasi dan Transesterifikasi
}

\author{
Isalmi Aziz*, Siti Nurbayti, Badrul Ulum \\ Program Studi Kimia FST UIN Syarif Hidayatullah Jakarta \\ Jl. Ir. H. Juanda No.95 Ciputat Jakarta 15412 \\ emi_uin@yahoo.co.id
}

\begin{abstract}
Abstrak
Biodiesel merupakan bahan yang sangat potensial untuk menggantikan bahan bakar solar. Bahan bakunya dapat diperbaharui dan bersifat ramah lingkungan. Minyak goreng bekas dapat digunakan sebagai bahan baku pembuatan biodiesel. Kadar asam le mak bebas yang tinggi dalam minyak goreng bekas memerlukan pretreatment (esterifikasi) dalam proses pembuatan biodiesel. Sehingga dalam penelitian ini dilakukan dua tahap reaksi yaitu esterifikasi dan dilanjutkan dengan tahap transesterifikasi. Pada tahap esterifikasi asam lemak bebas dapat diturunkan kadarnya dari 2,5\% menjadi $1,1 \%$. Tahap transesterifikasi didapatkan yield biodiesel sebesar $88 \%$. Karakteristik biodiesel yang dihasilkan yaitu: viskositas dan densitas pada suhu $40^{\circ} \mathrm{C}$ sebesar $3,2 \mathrm{cSt}$ dan 0,85 $\mathrm{g} / \mathrm{mL}$, kadar air $0,002 \%$, indeks setana 51 , titik nyala $176^{\circ} \mathrm{C}$, dan titik tuang $9^{\circ} \mathrm{C}$.
\end{abstract}

Kata kunci: Biodiesel, minyak goreng bekas, esterifikasi, transesterifikasi

\begin{abstract}
Biodiesel is a highly potential material to replace diesel fuel. Their raw materials are renewable and environmentally friendly. Frying oil can be used as raw material for making biodiesel. Free fatty acid levels are high in frying oils requiring pretreatment (esterification) in the process of making biodiesel. So in this study a two stages reaction of esterification and transesterification is carried out. At esterification of free fatty acid levels can be lowered from $2.5 \%$ to $1.1 \%$. At transesterification stage, yield biodiesel obtained is $88 \%$. Characteristics of biodiesel produced, namely: viscosity and density at a temperature of $40^{\circ} \mathrm{C}$ is $3.2 \mathrm{cSt}$ and $0.85 \mathrm{~g} / \mathrm{mL}$ respectively, water content is $0.002 \%$, cetane index is 51 , flash point is $176^{\circ} \mathrm{C}$, and pour point is $9^{\circ} \mathrm{C}$.
\end{abstract}

Keywords :._Biodiesel, cooking oil, esterificat ion, transesterification

\section{PENDAHULUAN}

Biodiesel merupakan bahan bakar yang ramah terhadap lingkungan. Biodiesel tidak mengandung berbahaya seperti $\mathrm{Pb}$, bersifat biodegradable, emisi gas buangnya juga lebih rendah dibandingkan emisi bahan bakar diesel. Biodiesel memiliki efek pelumasan yang tinggi sehingga dapat memperpanjang umur mesin dan memiliki angka setana yang tinggi ( $>50)$.

Minyak goreng bekas dapat digunakan sebagai bahan baku dalam proses pembuatan biodiesel. Minyak goreng bekas mengandung asam lemak bebas (Free Fatty Acid, FFA) yang dihasilkan dari reaksi oksidasi dan hidrolis is (Gambar 1) pada saat penggorengan.

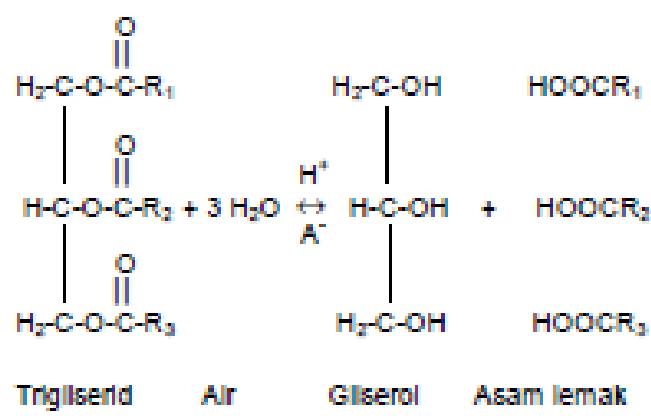

Gambar 1. Reaksi hidrolis is

Salah satu cara yang dapat dilakukan untuk menghilangkan asam lemak bebas adalah mereaksikan asam lemak bebas dengan alkohol dengan bantuan katalis asam sulfat. Reaksi ini dikenal dengan esterifikasi. Diharapkan dengan pretreatment ini dapat menurunkan kadar asam lemak bebas yang terdapat dalam minyak goreng bekas sehingga 
kualitas biodiesel yang dihasilkan akan lebih baik.

Reaksinya adalah sebagai berkut :

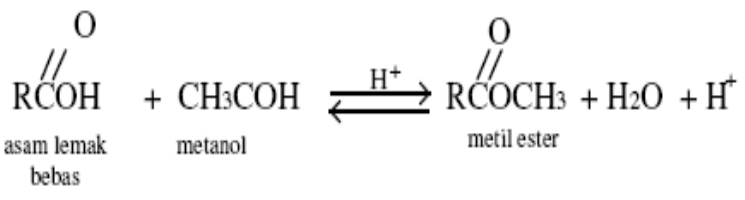

Gambar 2. Reaksi Esterifikasi
Transesterifikasi adalah suatu reaksi yang menghasilkan ester dimana salah satu pereaksinya juga merupakan senyawa ester. Jadi disini terjadi pemecahan senyawa trigliserida dan migrasi gugus alkil antara senyawa ester. Ester yang dihasilkan dari reaksi transesterifikasi ini disebut biodiesel. Reaksinya adalah sebagai berikut :<smiles></smiles>

Alkohol Trigliserida $\quad$ Ester/Biodiesel Gliserol

Gambar 3. Reaksi Transesterifikasi

Reaksi esterifikasi dan transesterifikasi merupakan reaksi bolak balik yang relatif lambat. Untuk mempercepat jalannya reaksi dan meningkatkan hasil, proses dilakukan dengan pengadukan yang baik, penambahan katalis dan pemberian reaktan berlebih agar reaksi bergeser ke kanan. Secara umum faktorfaktor yang mempengaruhi reaksi transesterifikasi adalah pengadukan, suhu, katalis, perbandingan pereaksi dan waktu reaksi (Darnoko and Cheriyan, 2000).

\section{Karak te ris asi B iodiese I}

Indonesia melalui Badan Standarisasi Nasional sudah menetapkan SNI untuk produk biodiesel yang sebagian parameternya tercantum dalam Tabel 1.

Tabel 1. Standar dan mutu biodiesel

\begin{tabular}{|c|l|c|c|c|}
\hline No. & \multicolumn{1}{|c|}{ Parameter } & Satuan & Nilai & Metode uji \\
\hline 1 & Massa jenis pada $40^{\circ} \mathrm{C}$ & $\mathrm{kg} / \mathrm{m}^{3}$ & $850-890$ & ASTM D 1298 \\
\hline 2 & Viskos itas kinematik pd $40{ }^{\circ} \mathrm{C}$ & $\mathrm{mm}^{2} / \mathrm{s}(\mathrm{cSt})$ & $2,3-6,0$ & ASTM D 445 \\
\hline 3 & Angka setana & & min. 51 & ASTM D 613 \\
\hline 4 & Titik nyala (mangkok tertutup) & ${ }^{\circ} \mathrm{C}$ & min. 100 & ASTM D 93 \\
\hline 5 & Titik kabut & ${ }^{\circ} \mathrm{C}$ & maks. 18 & ASTM D 2500 \\
\hline 6 & Air dan sedimen & $\%$-vol. & maks. 0,05* & $\begin{array}{c}\text { ASTM D 2709 } \\
\text { ASTM D-1796 }\end{array}$ \\
\hline 7 & Angka asam & mg-KOH/g & maks.0,8 & $\begin{array}{c}\text { AOCS Cd 3d-63 } \\
\text { ASTM D-664 }\end{array}$ \\
\hline
\end{tabular}

\section{METODE PENELITIAN}

Waktu dan Tempat
Penelitian ini berlangsung selama 3 bulan dari bulan Juli 2010 sampai September 2010. Tempat penelitian dilakukan di Pusat Laboratorium Terpadu (PLT) UIN Syarif 
Hidayatullah Jakarta dan untuk analisa karakteristik biodiesel dilakukan di LEMIGAS, Cileduk, Jakarta Selatan.

\section{Alat dan Bahan}

Alat yang digunakan dalam penelitian ini adalah GCMS, piknometer, Falling Ball Viscometer, labu leher tiga, pengaduk, termometer, kondensor. Bahan yang digunakan adalah minyak goreng bekas yang diambil dari pedagang kaki lima di sekitar kampus UIN Syarif Hidayatullah Jakarta, metanol, $\mathrm{KOH}$ dan asam sulfat.

\section{Sintes is Biodiesel}

Minyak goreng bekas $(450 \mathrm{ml})$ dimasukkan ke dalam labu leher tiga. Katalis asam sulfat $(0,25 \%$ berat minyak) dimasukkan ke dalam minyak dan dipanaskan sampai suhu yang diinginkan $\left(60^{\circ} \mathrm{C}\right)$. Metanol $(50 \mathrm{ml})$ ditempat terpisah juga dipanaskan sampai suhu yang diinginkan. Setelah suhu tercapai, metanol dimasukkan ke dalam minyak, pengaduk dihidupkan. Setelah 2,5 jam reaksi dihentikan kemudian diambil dan dianalisa kadar asam lemak bebasnya (FFA).

$\mathrm{KOH}$ ( $1 \%$ berat minyak) dilarutkan dalam metanol (100 ml) dan dipanaskan sampai suhu yang diinginkan $\left(60^{\circ} \mathrm{C}\right)$. Produk esterifikasi $(400 \mathrm{ml})$ dipanaskan dalam labu leher tiga dan ditambahkan larutan metoksida (metanol-KOH). Pengaduk dinyalakan. Setelah 1 jam reaksi dihentikan.Produk didiamkan dan ditimbang berat biodiesel yang dihasilkan.

Biodiesel yang dihasilkan terlebih dahulu dicuci dengan larutan garam jenuh sampai $\mathrm{pH}$ netral. Biodiesel yang sudah netral selanjutnya di analisa sifat fisik dan kimianya meliputi densitas, viskositas, kadar air, bilangan asam, titik nyala, titik tuang, komposisi senyawa penyusun dan angka csetana.

\section{HASIL DAN PEMBAHASAN}

Pretreatment (esterifikasi) yang dilakukan pada minyak goreng bekas mampu menurunkan kadar asam lemak bebas dari $2,5 \%$ menjadi $1,1 \%$ ( Gambar 4).

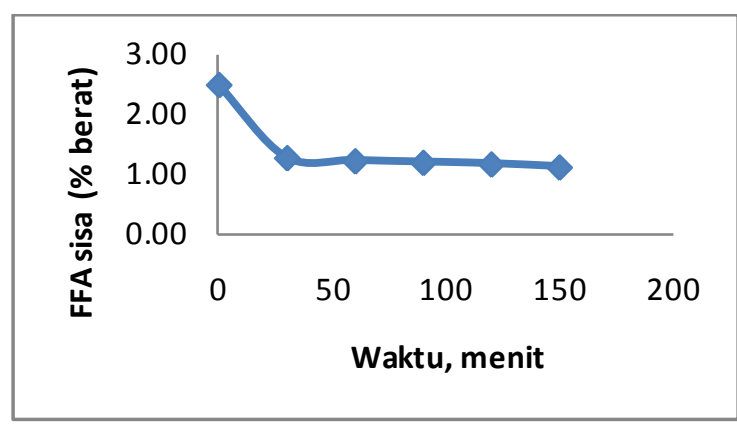

Gambar 4. Grafik hubungan waktu reaksi dengan \% FFA

Pada tahap transesterifikasi yield biodiesel yang dihasilkan mencapai 88\% (Gambar 5).

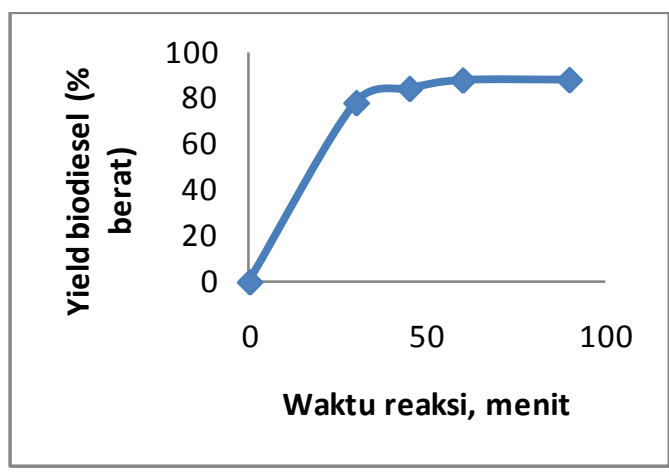

Gambar 5. Grafik hubungan waktu reaksi dengan Yield biodiesel

Biodiesel yang dihasilkan di analisa komposisinya menggunakan GCMs. Hasil analisa dapat dilihat pada Gambar berikut.

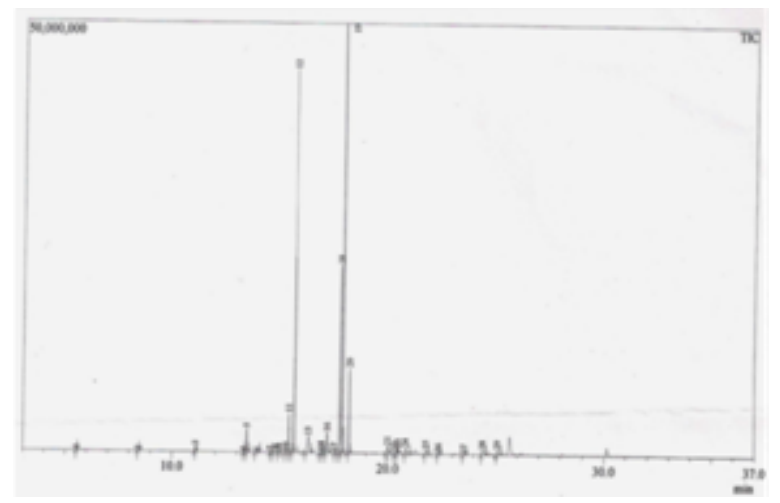

Gambar 6. Kromatogram biodiesel hasil analisa GCMS

Tabel 3 . Komposisi senyawa kimia dalam biodiesel hasil sintes is

\begin{tabular}{|c|c|c|l|c|}
\hline Puncak & $\begin{array}{c}\text { Luas } \\
\text { Puncak } \\
(\%)\end{array}$ & $\begin{array}{c}\text { Waktu } \\
\text { Retensi }\end{array}$ & Nama Senyawa & $\begin{array}{c}\text { Rumus } \\
\text { Molekul }\end{array}$ \\
\hline 1 & 0,06 & 5,537 & Metil oktanoat & $\mathrm{C}_{9} \mathrm{H}_{18} \mathrm{O}_{2}$ \\
\hline 2 & 0,03 & 8,452 & Metil kaprat & $\mathrm{C}_{13} \mathrm{H}_{22} \mathrm{O}_{2}$ \\
\hline 3 & 0,44 & 11,094 & Metil laurat & $\mathrm{C}_{13} \mathrm{H}_{26} \mathrm{O}_{2}$ \\
\hline 4 & 0,05 & 13,313 & $\begin{array}{l}\text { Metil Z-11- } \\
\text { tetradekenoat }\end{array}$ & $\mathrm{C}_{15} \mathrm{H}_{28} \mathrm{O}_{2}$ \\
\hline 5 & 1,70 & 13,456 & Metil miristat & $\mathrm{C}_{15} \mathrm{H}_{30} \mathrm{O}_{2}$ \\
\hline 6 & 0,03 & 13,928 & Metil nonadekanoat & $\mathrm{C}_{20} \mathrm{H}_{40} \mathrm{O}_{2}$ \\
\hline 7 & 0,12 & 14,548 & Metil & $\mathrm{C}_{16} \mathrm{H}_{32} \mathrm{O}_{2}$ \\
\hline
\end{tabular}




\begin{tabular}{|c|c|c|l|l|}
\hline & & & pentadekanoat & \\
\hline 8 & 0,26 & 14,791 & Metil arakidonat & $\mathrm{C}_{21} \mathrm{H}_{34} \mathrm{O}_{2}$ \\
\hline 9 & 0,27 & 14,948 & $\begin{array}{l}\text { Metil 5,8,11,14,1- } \\
\text { eukosapentanoat }\end{array}$ & \\
\hline 10 & 0,07 & 15,252 & Metil stearolat & $\mathrm{C}_{19} \mathrm{H}_{34} \mathrm{O}_{2}$ \\
\hline 11 & 2,81 & 15,393 & Metil palmitoleat & $\mathrm{C}_{17} \mathrm{H}_{32} \mathrm{O}_{2}$ \\
\hline 12 & 26,91 & 15,640 & Metil palmitat & $\mathrm{C}_{17} \mathrm{H}_{34} \mathrm{O}_{2}$ \\
\hline 13 & 1,17 & 16,294 & Metil 11 -eikosenoat & $\mathrm{C}_{21} \mathrm{H}_{40} \mathrm{O}_{2}$ \\
\hline 14 & 0,15 & 16,877 & Metil margarat & $\mathrm{C}_{18} \mathrm{H}_{36} \mathrm{O}_{2}$ \\
\hline 15 & 0,18 & 16,993 & $\begin{array}{l}\text { Metil cis-9,10- } \\
\text { epoksistearat }\end{array}$ & $\mathrm{C}_{19} \mathrm{H}_{36} \mathrm{O}_{2}$ \\
\hline 16 & 1,49 & 17,168 & Metil arakat & $\mathrm{C}_{21} \mathrm{H}_{42} \mathrm{O}_{2}$ \\
\hline 17 & 0,08 & 17,519 & $\begin{array}{l}\text { Metil } 6,9,12- \\
\text { oktadekatrienoat }\end{array}$ & $\mathrm{C}_{19} \mathrm{H}_{32} \mathrm{O}_{2}$ \\
\hline 18 & 13,17 & 17,753 & Metil linoleat & $\mathrm{C}_{19} \mathrm{H}_{34} \mathrm{O}_{2}$ \\
\hline 19 & 42,04 & 17,686 & Metil oleat & $\mathrm{C}_{19} \mathrm{H}_{36} \mathrm{O}_{2}$ \\
\hline 20 & 6,04 & 18,182 & Metil stearat & $\mathrm{C}_{19} \mathrm{H}_{38} \mathrm{O}_{2}$ \\
\hline
\end{tabular}

Dari Gambar di atas dapat diketahui komposisi senyawa terbesar adalah metil oleat $42,02 \%$ dan metil palmitat 26,91\%. Hasil analisa sifat fisik dan kimia lainnya dapat dilihat pada Tabel 2.

Tabel 2. Sifat fisik dan kimia biodiesel hasil sintes is

\begin{tabular}{|l|c|l|}
\hline \multicolumn{1}{|c|}{$\begin{array}{c}\text { Sifat fisik dan } \\
\text { kimia }\end{array}$} & $\begin{array}{c}\text { Biodiesel } \\
\text { penelitian } \\
\text { ini }\end{array}$ & \multicolumn{1}{|c|}{$\begin{array}{c}\text { SNI } \\
\text { Biodiesel }\end{array}$} \\
\hline Densitas $\left(40{ }^{\circ} \mathrm{C}\right), \mathrm{kg} / \mathrm{L}$ & 850 & $850-890$ \\
Viskositas kinematik & 3,2 & $2,3-6$ \\
$\left(40^{\circ} \mathrm{C}\right), \mathrm{cSt}$ & 0,5 & Maks. 0,8 \\
Bilangan asam, mg & 0,02 & Maks. 0,05 \\
$\mathrm{KOH} / \mathrm{g}$ Min.100 \\
Kadar air, \% vol & 176 & \\
Titik nyala, ${ }^{\circ} \mathrm{C}$ & 9 & Mak. 18 \\
Titik tuang, ${ }^{\circ} \mathrm{C}$ & 14,6 & Min. 51 \\
Titik kabut, ${ }^{\circ} \mathrm{C}$ & 51 & \\
Indeks Cetan & & \\
\hline
\end{tabular}

\section{Densitas}

Biodiesel yang dihasilkan dari penelitian ini mempunyai densitas pada suhu $40 \quad{ }^{\circ} \mathrm{C}$ sebesar $850 \mathrm{~kg} / \mathrm{L}$. Jika dibandingkan dengan standar SNI biodiesel, Biodiesel ini masuk dalam range yang ditetapkan. Densitas berkaitan dengan nilai kalor dan daya yang dihasilkan oleh mesin diesel. Densitas yang rendah akan menghasilkan nilai kalor yang tinggi.

Jika dibandingkan dengan densitas minyak goreng bekas yang digunakan sebagai bahan baku dalam proses pembuatan biodiesel, terjadi penurunan yang sangat tajam. Minyak goreng bekas yang mempunyai densitas $\left(40{ }^{\circ} \mathrm{C}\right) \quad 887$ $\mathrm{kg} / \mathrm{L}$, setelah dilakukan proses esterifikasi dan transesterifikasi densitas turun menjadi $850 \mathrm{~kg} / \mathrm{L}$. Ini disebabkan terjadinya pemutusan rantai gliserol yang terdapat dalam minyak goreng bekas (Aziz, 2008).

\section{Viskositas Kine matik}

Viskositas kinematik biodiesel seperti yang tercantum dalam Tabel 2 sebesar 3,2 cSt. Nilai ini masuk dalam standar SNI biodiesel yang ditetapkan pemerintah yaitu $2,3-6$ cSt. Viskositas mempunyai peranan yang sangat penting dalam proses penginjeksian bahan bakar. Viskositas yang terlalu rendah dapat menyebabkan kebocoran pada pompa injeksi bahan bakar dan kalau terlalu tinggi dapat mempengaruhi kerja cepat alat injeksi dan mempersulit pengabutan bahan bakar (Hardjono, 2001).

Viskositas biodiesel hasil penelitian ini lebih kecil dibandingkan dengan yang didapatkan Suirta (2009) sebesar 4,53 cSt. Bahan baku yang digunakan juga sama minyak goreng bekas tetapi sumber minyak goreng bekasnya berbeda. Perbedaan lainnya adalah jenis katalis yang digunakan. Suirta (2009) menggunakan $\mathrm{NaOH}$ sebagai katalis dalam reaksi transesterifikasi.

Jika dibandigkan dengan standar bahan bakar solar (1,6 - 5,8 sCt), biodiesel ini dari sisi viskositas masuk dalam standar yang ditetapkan sehingga biodiesel ini dapat digunakan sebagai bahan bakar pengganti solar.

\section{Bilangan asam}

Biodiesel yang dihasilkan mempunyai bilangan asam sebesar $0,5 \mathrm{mg}$ $\mathrm{KOH} / g$. Nilai ini memenuhi standar biodiesel yaitu maksimal $0,8 \mathrm{mg} \mathrm{KOH} / \mathrm{g}$. Jika ditinjau dari bilangan asam minyak goreng bekas sebesar 5,26 mg KOH/g dan $55 \%$ nya sudah dapat dihilangkan melalui pretreatment (reaksi esterifikasi) seharusnya sisa bilangan asam sebesar 2,367 $\mathrm{mg} / \mathrm{KOH}$. Besarnya selisih ini disebabkan karena sebagian besar asam 
lemak bebas sisa bereaksi dengan katalis $\mathrm{KOH}$ membentuk sabun. Ini ditandai dengan terbentuknya emulsi pada saat pencucian biodiesel dengan menggunakan air. Bilangan asam yang didapatkan dari penelitian ini lebih tinggi dari yang didapatkan Suirta (2009) yaitu 0,4238 mg $\mathrm{KOH} / \mathrm{g}$.

\section{Kadar air}

Kadar air yang terdapat dalam biodiesel sebesar 0,02\% volum. Kadar ini lebih kecil dibandingkan dengan SNI biodiesel yang mensyaratkan maksimal $0,05 \%$ volum. Begitu juga dengan standar bahan bakar solar mens yaratkan maksimal $0,05 \%$.

\section{Angka setana}

Kualitas bahan bakar solar dinyatakan dalam angka cetan dan dapat diperoleh dengan jalan membandingkan kelambatan menyala bahan bakar solar dengan kelambatan menyala bahan bakar pembanding dalam uji bangku CFR. Angka cetan biodiesel ini didapatkan dengan cara mengkonversikan nilai indek cetan yang diperoleh dari analisa yang dilakukan di Lemigas.

Menurut Hardjono (2001) angka setana nilainya lebih besar 2\% dibandingkan indek cetan. Angka cetan yang didapatkan sebesar 51,5. Nilai ini masuk dalam SNI biodiesel sehingga dilihat dari sisi angka setana, biodiesel hasil penelitian ini dapat digunakan sebagai bahan bakar pengganti solar.

\section{Titik nyala}

Titik nyala yang didapatkan sebesar 176 ${ }^{\circ} \mathrm{C}$. Nilai ini memenuhi standar bahan bakar solar dan SNI biodiesel. Titik nyala yang tinggi akan memudahkan penyimpanan bahan bakar, karena minyak tidak akan mudah terbakar pada temperatur ruang.

\section{Titik tuang dan titik kabut}

Bahan bakar solar harus dapat mengalir dengan bebas pada suhu atmosfer terendah dimana bahan bakar ini digunakan. Suhu terendah dimana bahan bakar diesel masih dapat mengalir disebut titik tuang (pour point). Pada suhu sekitar $10^{0} \mathrm{~F}$ di atas titik tuang bahan bakar solar dapat berkabut. Suhu ini dikenal dengan titik kabut.

Titik tuang yang diperoleh sebesar $9{ }^{\circ} \mathrm{C}$ atau $48,2{ }^{\circ} \mathrm{F}$. Standar solar mensyaratkan bahwa titik tuang maksimal $65^{\circ} \mathrm{F}$. Berarti biodiesel yang diperoleh dari penelitianini memenuhi standar bahan bakar solar.

Titik kabut dapat dicari dengan menggunakan data titik tuang. Dengan menambahkan 10 oC kepada titik tuang akan didapatkan nilai titik kabut (Hardjono, 2011). Titik kabut yang didapatkan dari perhitungan titik tuang sebesar $58,2{ }^{\circ} \mathrm{F}$ atau $14,6{ }^{\circ} \mathrm{C}$. ini berarti biodiesel yang dihasilkan memenuhi SNI biodiesel yang mensyaratkan titik kabut maksimal $18{ }^{\circ} \mathrm{C}$.

\section{KESIMPULAN DAN SARAN}

Dari penelitian yang sudah dilakukan dapat disimpulkan bahwa pretreatment yang dilakukan terhadap minyak goreng bekas mampu menurunkan kadar asam lemak bebas menjadi 1,1 \%. Yield biodiesel yang dihasilkan pada reaksi transesterifiksi sebesar $88 \%$. Kualitas biodiesel yang dihasilkan memenuhi SNI biodiesel yang ditetapkan pemerintah dan standar bahan bakar solar.

\section{UCAPAN TERIMAKASIH}

Pada kesempatan ini $\begin{array}{r}\text { penulis } \\ \text { mengucapkan terimakasih }\end{array}$
Lembada
Hidayatullah Jakarta yang telah mendanai
penelitian ini.

\section{DAFTAR PUSTAKA}

1. Aziz,I., 2007, Kinetika Reaksi Transesterifikasi Minyak Goreng Bekas", Valensi, Vol.1, No.1. 
2. Baidawi, A., Latif, I., dan Rachmaniah, O., 2008, Transesterifikasi dengan Co-Solvent sebagai salah satu alternatif Peningkatan Yield Metil Ester pada Pembuatan Biodiesel dari Crude Palm Oil (CPO), Chemical National Seminar, 26 Agustus 2008, Surabaya.

3. Buchori,L dan Widayat, 2009, “ Pembuatan Biodiesel dari Minyak Goreng Bekas dengan Proses Catalytic Cracking”, Prosiding Seminar Nasional Teknik Kimia Indonesia, Bandung.

4. Darnoko, D and Cheryan, M, 2000, "Kinetics of Palm Oil Transeterification in a Batch Reactor", J. Am.Oil Chem.Soc., 77, 12631267.

5. Hardjono, A., 2000, “ Teknologi minyak Bumi “, Gadjah Mada University Press, Yogyakarta.

6. Kusmiyati, 2008, “ Reaksi Katalitis Esterifikasi Asam Oleat dan Metanol menjadi Biodiesel dengan Metode Distilasi Reaktif', Jurnal Reaktor, Vol.12, No.2. Hal. 78-82.

7. Suirta, I.W., 2009, “ Preparasi Biodiesel dari Minyak Jelantah Kelapa Sawit”, Jurnal Kimia, Vol.3. No.1, 1-6.

8. Susanto, BH., Nasikin, M., dan Sukirno, 2008 " Sintesis Pelumas Dasar Bio melalui Esterifikasi Asam Oleat menggunakan Katalis Asam Heteropoli/Zeolit", Prosiding Seminar Nasional Rekayasa Kimia dan Proses, Semarang. 